\title{
The Impact of Renal Dialysis on Hospital Separations: The Case of Pacific Island Communities in the State of Queensland, Australia
}

\author{
Prof. YEBOAH David Achanfuo
}

\author{
Professor of Epidemiology, Abu Dhabi University.
}

Article No.: 012315014

Type: Research

DOI: 10.15580/GJMS.2015.2.012315014

Submitted: 23/01/2015

Accepted: 10/04/2015

Published: $20 / 04 / 2015$

*Corresponding Author

David Achanfuo Yeboah

E-mail: david.yeboah@adu.ac.ae

\section{Keywords:}

Renal Dialysis, Renal Hospital

Separations, Pacific Island

Communities, Queensland
The issue of hospital morbidity, and in particular hospital admissions, has been discussed over and over again in Australia and other jurisdictions. There has always been the perceived position that some conditions necessitate repeat visits to hospital and put undue pressure on the Queensland hospital system and its associated resources. This study investigates hospital morbidity among the Pacific Island communities in Queensland. The specific objective is to establish the contribution of renal dialysis to total hospital separations in general and avoidable hospital separations in particular. The study found that conditions such as diabetes complications contribute strongly to hospital separations of the Pacific Island communities, and that the marginal effect of renal dialysis was large. The standardised separation ratio (SSR) for all causes was more than halved when renal dialysis was excluded. The study concludes that renal dialysis contributes strongly to hospital morbidity and hospital separations of Pacific Island communities in Queensland, Australia. The study concludes further that the very strong contribution of renal dialysis to hospital separations can be reduced with improvements in the management of chronic disease. 


\section{INTRODUCTION}

The substantial contribution of chronic disease to the burden of disease has been recognised in many countries and acknowledged in the health research literature of Queensland (Duckett, 2009). The cost of in-patient hospital services is rising all over Australia due to high hospital separations. Diabetes complications and, in particular, renal dialysis, are known to contribute strongly to the utilisation of inpatient hospital services and subsequent separations. The issue of the increasing costs of chronic disease related hospitalisation and its undue impact on the health budget of Queensland and other jurisdictions continues to be discussed unabated (Duckett, 2009). A key theme in these discussions appears to focus on the contribution of specific medical conditions to hospital morbidity and hospital costs. Chronic diseases in particular appear to feature highly in the medical conditions which usually result in hospitalisation and Queensland Health has identified a number of inscope conditions which constitute the major areas of chronic disease burden (Queensland Health, 2006).

More importantly, the available epidemiological data point to a strong contribution of diabetes complications to the total number of hospital separations and, within these complications, renal dialysis (especially end stage renal dialysis) accounts for a substantial proportion of the hospital separations. There is also evidence to suggest that a large number of hospitalisations can be avoided, if the potential patients receive adequate care at the primary care level. Consistent with this evidence, Queensland Health provides a framework for self-management of chronic disease, which aims at assisting people to better manage their chronic disease and reduce preventable hospital admissions (Queensland, 2009).

The large numbers of avoidable or preventable hospital separations presuppose a need to establish the nature and level of avoidable hospital separations with a view to developing strategies and policies to reduce them. As indicated later in this study, renal dialysis accounts for a substantial proportion of avoidable hospital separations in the Pacific Island communities of Queensland.

\section{Objectives}

The purpose of this study is, therefore, to examine hospital morbidity data for the Pacific Island people of Queensland and attempt to identify the contribution of renal dialysis to the hospital separations of those communities. This paper provides specific information on the hospital separations of the Pacific Island communities of Queensland, particularly avoidable hospital separations and the impact of renal dialysis. It also suggests some strategies to reduce the high separations. In particular, this study's primary objective is to indicate the contribution of renal dialysis to hospital separations caused by diabetes complications as well as the impact of renal dialysis on total avoidable hospital separations.
Identifying the contribution of high in-patient services utilisation conditions, such as renal dialysis and other diabetes complications, has the potential to enhance policy and program development to reduce their impact on hospital services. Besides, there are expectations for hospital services providers to reduce cost through the overall reduction in the utilisation of hospital services together with the efficient delivery of services. The identification of areas of major burden on the in-patient hospital services in Queensland can therefore contribute to the achievement of these expectations. This identification can also inform planning and resource allocation decisions and result in the delivery of effective and efficient in-patient hospital services (see also McDonald et. at., 2003). .Hence, the added significance of this study.

\section{SOURCES OF DATA AND METHODOLOGIES}

The main source of data for this study is the Queensland Health Admitted Patient Data Collection, usually referred to as QHAPDC. This database is held and managed by the organization's Health Statistics Centre and contains unit record data on all in-patient hospital separations in Queensland.

The methodologies involve the scientific selection of 5 Pacific Island countries and the epistatistical analysis of hospital separation data related to those populations. The selected communities are the Cook Islands, Fiji, Papua New Guinea (PNG), Samoa and Tonga. Indirect age standardisation of the hospital morbidity data at $95 \%$ confidence interval was undertaken using the Queensland population of 2006 as standard. Average counts of hospital episodes are derived, expected counts and standardised separation ratios (SSRs) are computed as part of the standardisation process. The statistical analysis is undertaken for all causes as well as for the selected inscope conditions, which are consistent with Queensland Health's priority areas for chronic disease. According to Queensland Health (2006), these inscope or priority conditions include cancers of all sites, renal failure, diabetes complications, Coronary Heart Disease, Stroke, and Chronic Obstructive Pulmonary Disease (COPD).

\section{FINDINGS}

Table 1 shows the average yearly counts and estimated expected counts of hospital separations, standardised separation ratios, confidence intervals and statistical significance for all causes among the Queensland population born in the selected Pacific Island countries. The SSRs were high with Samoa (198.3, $\mathrm{p}=0.001$ ), Tonga (164.0, $\mathrm{p}=0.001$ ) and the Cook Islands $(131.8, p=0.001)$ recording the highest SSRs. With the exception of Fiji, the SSRs for the other countries of birth were statistically significant. 
Table 1: Indirect age standardised separation ratios for all causes, selected Pacific Island countries, 2007-08

\begin{tabular}{|l|l|l|l|l|l|l|}
\hline $\begin{array}{l}\text { Country of } \\
\text { birth }\end{array}$ & $\begin{array}{l}\text { Expected } \\
\text { counts }\end{array}$ & $\begin{array}{l}\text { Average } \\
\text { yearly } \\
\text { counts }\end{array}$ & SSR & $\begin{array}{l}\text { Lower 95\% } \\
\text { C I imit }\end{array}$ & $\begin{array}{l}\text { Upper 95\% } \\
\text { C I limit }\end{array}$ & $\begin{array}{l}\text { Statistical } \\
\text { significance }\end{array}$ \\
\hline Cook Island & 409.3 & 539.5 & 131.8 & 129.8 & 143.4 & 0.001 \\
\hline Fiji & 3375.1 & 3477.5 & 103.0 & 99.6 & 106.5 & 0.101 \\
\hline PNG & 4358.3 & 4757.5 & 109.2 & 106.1 & 112.3 & 0.005 \\
\hline Samoa & 1838.8 & 3647.0 & 198.3 & 192.0 & 204.9 & 0.001 \\
\hline Tonga & 442.2 & 725.0 & 164.0 & 152.2 & 176.3 & 0.001 \\
\hline
\end{tabular}

Source: Computed from data from Queensland Health Admitted Patient Data Collection

Table 2 shows expected counts, average yearly counts, statistically significant SSRs for COPD. All the indirect age standardised separation ratios and statistical communities recorded statistically significant SSRs for significance status of the Queensland Health in-scope diabetes complications (table 2). The Cook Islands SSR priority conditions. Fiji recorded the highest SSR for of $955.2 \quad(p=0.001)$ was the highest for diabetes Coronary Heart Disease (212.8) and this was statistically complications while the lowest SSR was found with the significant $(\mathrm{p}=0.001)$. Table 2 shows further that the PNG born (88.6). The highest SSR for all cancers was Pacific Island communities of Queensland recorded found in the PNG born (119.8, $p=0.005)$ and the lowest SSRs for stroke, which were not statistically significant, in the Fiji born community $(68.6, p=0.001)$, and they while Samoa (229) and PNG (85.3) recorded high were both statistically significant.

Table 2: Indirect standardised separations ratios, selected in-scope conditions, Pacific Island communities of Queensland 2007-06

\begin{tabular}{|c|c|c|c|c|c|c|c|}
\hline $\begin{array}{ll}\text { In-scope or } \\
\text { Priority } \\
\text { Condition }\end{array}$ & $\begin{array}{l}\text { Country } \\
\text { of birth }\end{array}$ & $\begin{array}{l}\text { Expected } \\
\text { counts }\end{array}$ & $\begin{array}{l}\text { Average } \\
\text { yearly } \\
\text { counts }\end{array}$ & SSR & $\begin{array}{l}\text { Lower } \\
95 \% \text { C } \\
\text { I limit }\end{array}$ & $\begin{array}{l}\text { Upper } \\
95 \% \\
\text { C I limit }\end{array}$ & $\begin{array}{l}\text { Statistical } \\
\text { significance }\end{array}$ \\
\hline \multirow[t]{5}{*}{$\begin{array}{l}\text { Coronary Heart } \\
\text { Disease }\end{array}$} & $\begin{array}{l}\text { Cook } \\
\text { Islands }\end{array}$ & 6.6 & 10.5 & 159.3 & 77.8 & 288.5 & 0.001 \\
\hline & Fiji & 63.9 & 136 & 212.8 & 178.6 & 251.8 & 0.001 \\
\hline & PNG & 70.9 & 66.0 & 93.1 & 72.0 & 118.4 & 0.005 \\
\hline & Samoa & 35.4 & 43.0 & 121.5 & 87.9 & 163.6 & 0.001 \\
\hline & Tonga & 9.1 & 9.5 & 104.9 & 48.8 & 195.0 & 0.001 \\
\hline \multirow[t]{5}{*}{ Stroke } & $\begin{array}{l}\text { Cook } \\
\text { Islands }\end{array}$ & & 5 & - & - & - & - \\
\hline & Fiji & 12.1 & 12.5 & 103.3 & 54.2 & 178.5 & 0.013 \\
\hline & PNG & 13.3 & 13.5 & 101.5 & 54.7 & 171.9 & 0.021 \\
\hline & Samoa & 6.3 & 9.5 & 150.8 & 70.6 & 281.6 & 0.011 \\
\hline & Tonga & & $<5$ & - & - & - & - \\
\hline \multirow[t]{5}{*}{ COPD } & $\begin{array}{l}\text { Cook } \\
\text { Islands }\end{array}$ & & $<5$ & - & - & - & - \\
\hline & Fiji & 17.4 & 8.0 & 45.9 & 19.8 & 90.6 & 0.001 \\
\hline & PNG & 18.2 & 15.5 & 85.3 & 48.1 & 139.4 & 0.001 \\
\hline & Samoa & 9.2 & 21.0 & 229.4 & 141.2 & 348.9 & 0.001 \\
\hline & Tonga & & $<5$ & - & - & - & - \\
\hline \multirow[t]{5}{*}{$\begin{array}{l}\text { Diabetes } \\
\text { complications }\end{array}$} & $\begin{array}{l}\text { Cook } \\
\text { Islands }\end{array}$ & 17.4 & 168.0 & 955.2 & 814.4 & 1110.7 & 0.005 \\
\hline & Fiji & 294.0 & 580.0 & 497.3 & 181.5 & 214.0 & 0.001 \\
\hline & PNG & 326.0 & 323.0 & 399,1 & 88.6 & 110.5 & 0.001 \\
\hline & Samoa & 90.3 & 664.0 & 735.5 & 580.5 & 793.4 & 0.001 \\
\hline & Tonga & 23.4 & 136.0 & 581.1 & 487.6 & 687.5 & 0.001 \\
\hline \multicolumn{8}{|l|}{ All Cancers } \\
\hline & $\begin{array}{l}\text { Cook } \\
\text { Islands }\end{array}$ & 13.3 & 11.0 & 82.4 & 41.2 & 148.0 & 0.001 \\
\hline & Fiji & 325.0 & 223.0 & 68.6 & 59.9 & 78.2 & 0.005 \\
\hline & PNG & 373.0 & 447.0 & 119.8 & 109.0 & 132.5 & 0.001 \\
\hline & Samoa & 23.1 & 22.0 & 95.4 & 59.7 & 144.2 & 0.001 \\
\hline & Tonga & 16.8 & 19.5 & 115.9 & 70.4 & 180.2 & 0.001 \\
\hline
\end{tabular}

Source: Computed from data from Queensland Health Admitted Patient Data Collection 
Hospital separations due to diabetes complications (excluding renal dialysis) are presented in table 3 . The Cook Island recorded the highest SSR of 402.9 $(p=0.001)$, followed by Samoa (322.6, $p=0.001)$, Fiji (229.4, $\mathrm{p}=0.001$ ) and Tonga (211.7, $\mathrm{p}=0.001)$. PNG's SSR of 96.7 was the lowest, but it was also statistically significant. Clearly the SSRs for hospital separations due to diabetes complications decreased in magnitude when renal dialysis was excluded (tables 2 and 3). For example, Cook Islands' SSR decreased from 955 for diabetes complications (including renal dialysis) to 402 when renal dialysis is excluded, a decrease of $58 \%$, while the decrease was about $56 \%$ for Samoa.

Table 3: Age standardised hospital separation rates due to diabetic complications, selected Pacific Island communities in Queensland 2007-08, (excluding renal dialysis)

\begin{tabular}{|l|l|l|l|l|l|l|}
\hline $\begin{array}{l}\text { Country of } \\
\text { birth }\end{array}$ & $\begin{array}{l}\text { Expected } \\
\text { counts }\end{array}$ & $\begin{array}{l}\text { Average } \\
\text { yearly } \\
\text { counts }\end{array}$ & SSR & $\begin{array}{l}\text { Lower 95\% } \\
\text { confidence } \\
\text { interval }\end{array}$ & $\begin{array}{l}\text { Upper 95\% } \\
\text { confidence } \\
\text { interval }\end{array}$ & $\begin{array}{l}\text { Statistical } \\
\text { significance }\end{array}$ \\
\hline $\begin{array}{l}\text { Cook } \\
\text { Islands }\end{array}$ & 14.8 & 59.5 & 402.9 & 306.4 & 518.0 & 0.001 \\
\hline Fiji & 142.1 & 326.0 & 229.4 & 205.2 & 256.7 & 0.001 \\
\hline PNG & 157.1 & 177.0 & 112.7 & 96.7 & 130.5 & 0.005 \\
\hline Samoa & 76.7 & 247.6 & 322.6 & 283.7 & 365.5 & 0.001 \\
\hline Tonga & 20.1 & 42.5 & 211.7 & 152.7 & 285.3 & 0.001 \\
\hline
\end{tabular}

Source: Computed from data from Queensland Health Admitted Patient Data Collection

Table 4 shows that total avoidable hospital separations were high for the Pacific Island communities of Queensland, with the Cook Islands (508.7, $\mathrm{p}=0.001)$, Samoa (460.2, $p=0.001)$ and Tonga (420.1, $p=0.001)$ recording the highest SSRs. All the SSRs were statistically significant except PNG which also recorded the lowest SSR for total avoidable separations of 91.6. Table 4 shows further that the SSRs for avoidable hospital separations decreased substantially when renal dialysis was excluded for all the countries, All the ratios were statistically significant except that for PNG.

Table 4: Total avoidable hospital separations, Pacific Island communities, Queensland, 2007-08

\begin{tabular}{|c|c|c|c|c|c|c|c|}
\hline $\begin{array}{l}\text { Total } \\
\text { avoidable } \\
\text { separations }\end{array}$ & Country & $\begin{array}{l}\text { Expected } \\
\text { counts }\end{array}$ & $\begin{array}{l}\text { Average } \\
\text { yearly } \\
\text { counts }\end{array}$ & SSR & $\begin{array}{l}\text { Lower } \\
95 \% \text { C } \\
\text { I Limit }\end{array}$ & $\begin{array}{l}\text { Higher } \\
95 \% \text { C I } \\
\text { Limit }\end{array}$ & $\begin{array}{l}\text { Statistical } \\
\text { significance }\end{array}$ \\
\hline & $\begin{array}{l}\text { Cook } \\
\text { Islands }\end{array}$ & 30.2 & 153.5 & 508.7 & 431.0 & 595.4 & 0.001 \\
\hline & Fiji & 257.0 & 299.5 & 116.5 & 103.7 & 130.5 & 0.001 \\
\hline & PNG & 313.8 & 287.5 & 91.6 & 81.3 & 102.8 & 0.131 \\
\hline & Samoa & 137.4 & 632.5 & 460.2 & 425.2 & 497.7 & 0.001 \\
\hline & Tonga & 34.3 & 144.0 & 420.1 & 354.1 & 454.3 & 0.005 \\
\hline \multicolumn{8}{|c|}{ Total avoidable separations excluding renal dialysis } \\
\hline & $\begin{array}{l}\text { Cook } \\
\text { Islands }\end{array}$ & 27.8 & 47.0 & 170.5 & 125.1 & 226.5 & 0.001 \\
\hline & Fiji & 232.8 & 293.5 & 66.1 & 112.1 & 141.4 & 0.005 \\
\hline & PNG & 286.3 & 284.0 & 79.2 & 88.0 & 111.4 & 0.212 \\
\hline & Samoa & 123.9 & 216.0 & 174.3 & 151.9 & 199.2 & 0.001 \\
\hline & Tonga & 31.0 & 50.5 & 163.1 & 121.1 & 214.5 & 0.001 \\
\hline
\end{tabular}

Source: Computed from data from Queensland Health Admitted Patient Data Collection

\section{DISCUSSION}

That hospital morbidity impacts strongly on the health budget is not in question. The present study adds to the ongoing discussion about reducing the costs associated with in-patient hospital services by providing specific information and analysis on Pacific Island communities of Queensland. The object is to delineate the contribution of specific conditions, such as renal dialysis, to the utilisation of in-patient hospital services. These communities have high SSRs for all causes of hospital separations and even higher SSRs for avoidable hospital separations and hospital separations due to diabetes complications. High SSRs translate into high utilisation of in-patient hospital services and high cost, which in turn places much 
pressure on the hospital services component of the health budget.

This presupposes a need to develop or identify strategies to reduce avoidable hospital separations. To develop effective strategies to minimize the incidence and prevalence of chronic disease among Pacific Islanders of Queensland, the causes of the conditions must first be established. There is some evidence in the literature corroborating the position that diet and nutrition, physical inactivity, poor or rather inadequate management of existing conditions, obesity and lack of knowledge about chronic disease prevention are the leading causes (see, for example, Chand. 2010; Queensland Health 2006 and Queensland Health 2008). These causal factors are prevalent in the Pacific Island communities of Queensland, hence the high SSRs found in this study.

It is notable that Queensland Health has developed a couple of useful documents on selfmanagement of chronic disease and strategies to prevent chronic disease (Queensland Health, 2009). These documents have the potential to reduce hospital separations due to chronic disease and, in particular, avoidable separations. Successful implementation of the proposals in the documents can also reduce costs and improve the overall performance of the Queensland health system.

In relation to the Pacific Island communities of Queensland, these documents could reduce the high SSRs presented earlier in this article, but the contents of the documents must be widely disseminated among the communities. For the Pacific Island communities of Queensland, evidence from the study points to high contributions of diabetes complications to high hospital separations and high avoidable hospital admissions which translate into avoidable hospital separations. This study shows that hospital separations due to diabetes complications and total avoidable separations can be reduced if hospital separations caused by renal dialysis is reduced. For the Cook Islands, SSR for diabetes complications decreased by $58 \%$ from 955.2 to 402.9. The SSR for diabetes complications for the Tonga community declined from 581.1 to 211.7 when renal dialysis is excluded, a decrease of over $63 \%$. For the Samoan community, SSR due to diabetes complications decreased from 735.5 to 322.6 when renal dialysis is excluded, a decline of $56.1 \%$. Clearly, for Queensland's Pacific Island communities, renal dialysis was a strong contributor to hospitalisations caused by diabetes complications during 2007-08.

Similar patterns were found for avoidable hospital separations. The SSRs declined sharply when renal dialysis was excluded, which meant that renal dialysis made a substantial difference to hospitalisation among the Pacific Island communities of Queensland. For the Cook Islands, the SSR declined by over $66.5 \%$ when renal dialysis was excluded, while the corresponding reductions for the Samoa and Tongan communities were $62.1 \%$ and $61.2 \%$ respectively. The strong contribution of diabetes complications, especially renal dialysis, is consistent with the evidence in the literature. The point must also be made that the burden of renal disease among the Pacific
Island communities of Queensland was different from the other population subgroups in the State, but consistent with similar level of burden identified for other population subgroups in Australia as a whole (see also McDonald et al., 2003).

\section{Strategies}

This high contribution of renal dialysis and other diabetes complications to avoidable separations leads to the proposition for health systems to develop and deliver strategies to better manage diabetes at the primary care level before complications set in. For the Pacific Island communities of Queensland, such strategies would reduce the utilisation of in-patient hospital services, reduce cost and redirect resources to other needy areas of the health system. Opportunities for the prevention of chronic disease among Queensland's Pacific Island communities must be sought and utilised. Clearly, prevention is the key and the main instrument for ensuring reductions in chronic disease hospital separations. Effective strategies can only be developed and implemented if the underlying causes of the excessive utilization of inpatient hospital services are identified. According to Glover (2007), for Australia as a whole, the key factors include socioeconomic status, individuals own perceptions of their health needs as well as their health care choices. The last two relate to education. Glover (2007) contends further that the highest use of in hospital services and, especially, avoidable hospital admissions occurred in the oldest and most disadvantaged Australians. Pacific Island communities are very disadvantaged so much so as to be branded invisible (Chand, 2010), have lower educational achievement than other Australians (which impacts on their health choices and perceptions) and are not very proficient in English to digest and understand the content of health brochures. The following proposed strategies would address some of these concerns.

The need for preventive and control strategies to reduce the incidence and prevalence of diabetes complications cannot be overemphasised (see, for example, Dowrick, 2006). Prevention has been noted in the literature as an effective strategy for controlling the prevalence of chronic disease and the associated complications (Folaci and Pearce, 2003). It is also important to have in place a strategy which would put the onus on the communities and patients to rake full responsibility for the management of their conditions, and to assume an effective role in the care model (working with their care team to improve their health). Patient self-management is a key strategy in the Queensland Strategy for Chronic Disease, and proper self management has the potential to reduce service utilisation especially the number and proportion of frequent users (Queensland Health, 2006).

However, the challenge is how to disseminate information successfully on self-management in the Pacific Island communities. The strategies and associated objectives enshrined in the Queensland Health self-management strategy would be successfully achieved only if the communities are 
made aware and informed (see, for example, Coulter, 2007. Previous studies have demonstrated clearly the association between effective self management of chronic disease and reduction in service utilisation and hospital costs (Long et al., 2001). The findings of this study show that the prevention of diabetes complications, especially renal dialysis, would reduce the utilisation of in-patient hospital services and reduce overall cost (table 4).

There is evidence in the literature alluding to the position that patient confidence and health education are essential if any self-management strategy is to work (Norris et al., 2002). Self confidence or self-efficacy, as it has been known, is crucial and can be achieved through the provision of information directly to the patient. This study contends that selfefficacy would benefit from the use of community based support networks and there are numerous Pacific Island community networks in Queensland (Chand, 2010). Closely related to this is the need for continuous monitoring and evaluation of the strategy and the patients' progress. Another potentially effective strategy to reduce the prevalence of diabetes complications and particularly renal dialysis is education. This strategy involves informing and educating Pacific Island communities about the risk factors and how to avoid becoming sick with diabetes and also how to better manage the diabetes to prevent complications. The need to involve patients in decisions on education and other preventive measures is also essential and has been effective in other jurisdictions. So also is the need to develop local based strategies involving local conditions (Yeboah 2005) and the delivery of linguistically and culturally appropriate programs (Yeboah, 2000). Any strategies presented to the Pacific Island communities of Queensland must take into consideration the norms, value, beliefs and perceptions of health to achieve the desired objectives; this view is corroborated by Glover, 2007.

Finally, the low employment of Pacific Island people needs to addressed, albeit this is external to the health sector. Low employment means generally that the Pacific Island population would have low incomes, be under continuous stress as they look for work, and will have difficulty paying for healthcare. A comprehensive approach involving various sectors and Pacific Island community networks will be in order.

\section{CONCLUSION}

The study concurs with the general notion that hospital morbidity is high in Queensland, especially among population minorities such as Pacific Islanders. As hospital morbidity is a major burden on the State's health budget, efforts need to be directed at reducing high level of hospital services utilisation. It is also the conclusion of the study that specific conditions such as renal dialysis (caused by diabetes complications), attract high utilisation as individuals can record many episodes of hospitalisation. The study concludes that hospital separations resulting from diabetes complications were high for the Pacific Island communities, albeit this was consistent with the large number of diabetes related hospital admissions for the State as a whole. The study concludes further that a reduction in diabetes complications among the Pacific Island populations would reduce their use of in-patient services, and reduce costs.

The massive reduction in SSR when renal dialysis is excluded leads to the conclusion that renal dialysis is a major burden among the Pacific Islanders communities of Queensland. The standpoint taken in this study is that a health care strategy which will lead to the effective management of diabetes and related chronic disease patients at the primary care level is crucial to reduce the impact of renal dialysis. So also is the need for better self management of chronic disease among the Pacific Islander population of Queensland. In particular renal dialysis and other diabetes complications should be avoided through the proper management of the diseases by GPs and specialist clinicians outside the hospital as well as through effective community based self management programs. This would inevitably result in the reduction of avoidable hospital separations not only for the Pacific Island communities, but also for the Queensland population as a whole.

\section{ACKNOWLEDGEMENTS}

The author acknowledges the assistance of Sarah Muller (Queensland Health) in relation to the data used in this study. The author further extends his immense gratitude and appreciation to Tracey Maree Yeboah for proof reading and other contributions.

\section{REFERENCES}

Chand, M (2010): Health stratus of Pacific Island populations in Queensland. Brisbane, Queensland Health.

Coulter, A., (2007): The effectiveness of strategies for informing, educating and involving patients. British Medical Journal, 335: 24-27.

Dowrick, G. (2006): The chronic disease strategy for Australia. Medical Journal of Australia, 185 (2): 6162.

Duckett, S. J. (2009): Are we ready for the next big step? Medical Journal of Australia, 190 (12): 687688.

Folaki, S.., and Pearce, N. (2003): Prevention and control of diabetes in Pacific people. British Medical Journal, 327.

Glover, J (2007): Atlas of avoidable hospitalizations in Australia: Ambulatory care-sensitive conditions. Adelaide, Australian Institute of Health and Welfare.

Long, K. R., Ritter, P, Stewalt, A. L, Sobel, D. S., Brown, B. W., er al.(2001) Chronic disease selfmanagement program: 2-year health status and health care utilisation outcomes. Medical Care, 39 (11): 1217-1223. 
McDonald, S., and Ross, G. (2003): Burden of endstage renal disease among indigenous people in Australian and New Zealand. Kidney International, 83:5123-5127.

Norris, S. L., Nichols, P. J., Carspersen, C. J., Glasgow, R. E., Engelgau, M. M., Jack, L., et al. (2002): Increasing diabetes self-management education in community settings: A systematic review. American Journal of Preventive Medicine, (4): 39-66.

Queensland Health. (2006): Queensland Strategy for Chronic Disease 2005-2011. Brisbane, Queensland Health.
Queensland Health. (2008): The health of Queenslanders: Prevention of chronic disease... Brisbane, Queensland Health.

Queensland Health. (2009): Framework for selfmanagement 2008-2015. Brisbane, Queensland Health.

Yeboah, D. A. (2000): Culturally appropriate health service in Australia and New Zealand. In Handbook of Global Technology Policy, Nagel S (Ed), New York, Marcel Dekker, Inc: 251-260.

Yeboah, D A. (2005) A framework for place based health planning. Australian Health Review, 27 (3), 41-50.

Cite this Article: Yeboah, DA (2015).The impact of renal dialysis on hospital separations: The case of Pacific Island communities in the State of Queensland, Australia. Greener Journal of Medical Sciences, 5(2):026-032, http://doi.org/10.15580/GJMS.2015.2.012315014.. 